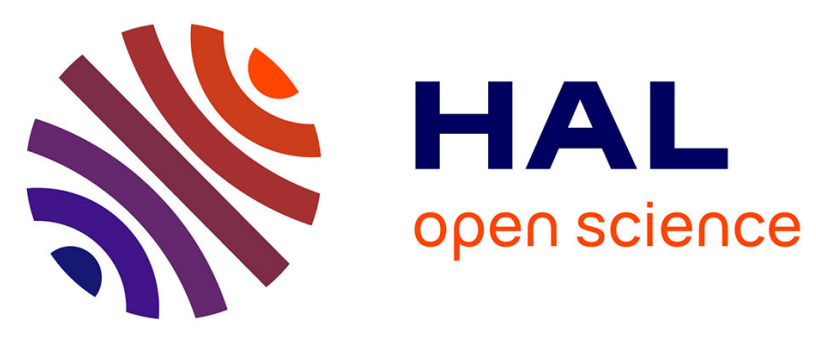

\title{
Monogenic forms of lipodystrophic syndromes - diagnosis, detection, and practical management considerations from clinical cases
}

Camille Vatier, Marie-Christine Vantyghem, Caroline Storey, Isabelle Jéru, Sophie Christin-Maitre, Bruno Fève, Olivier Lascols, Jacques Beltrand, Jean-Claude Carel, Corinne Vigouroux, et al.

\section{To cite this version:}

Camille Vatier, Marie-Christine Vantyghem, Caroline Storey, Isabelle Jéru, Sophie Christin-Maitre, et al. Monogenic forms of lipodystrophic syndromes - diagnosis, detection, and practical management considerations from clinical cases. Current Medical Research and Opinion, 2019, 35 (3), pp.543-552. 10.1080/03007995.2018.1533459 . hal-02272036

\section{HAL Id: hal-02272036 https://hal.sorbonne-universite.fr/hal-02272036}

Submitted on 27 Aug 2019

HAL is a multi-disciplinary open access archive for the deposit and dissemination of scientific research documents, whether they are published or not. The documents may come from teaching and research institutions in France or abroad, or from public or private research centers.
L'archive ouverte pluridisciplinaire HAL, est destinée au dépôt et à la diffusion de documents scientifiques de niveau recherche, publiés ou non, émanant des établissements d'enseignement et de recherche français ou étrangers, des laboratoires publics ou privés. 


\section{Monogenic forms of lipodystrophic syndromes - diagnosis, detection, and practical management considerations from clinical cases}

Camille Vatier, ${ }^{\mathrm{a}, \mathrm{b}}$, Marie-Christine Vantyghem ${ }^{\mathrm{c}}$, Caroline Storey ${ }^{\mathrm{d}, \mathrm{e}}$, Isabelle Jéru ${ }^{\mathrm{b}, \mathrm{f}}$, Sophie Christin-Maitre $^{\mathrm{a}, \mathrm{g}}$, Bruno Fève ${ }^{\mathrm{a}, \mathrm{b}}$, Olivier Lascols ${ }^{\mathrm{b}, \mathrm{c}}$, Jacques Beltrand ${ }^{\mathrm{h}}$, Jean-Claude Carel $^{\mathrm{d}, \mathrm{e}}$, Corinne Vigouroux ${ }^{\mathrm{a}, \mathrm{b}, \mathrm{f}}$, Elise Bismuth ${ }^{\mathrm{d}, \mathrm{e}}$

aAssistance Publique-Hôpitaux de Paris (AP-HP), Hôpital Saint-Antoine, Centre de Référence des Pathologies Rares de l'Insulino-Sécrétion et de l'Insulino-Sensibilité (PRISIS), Service d'Endocrinologie, Diabétologie et Endocrinologie de la Reproduction, F-75012, Paris, France

bSorbonne Université, Inserm, Centre de Recherche Saint-Antoine, Institut HospitaloUniversitaire de Cardio-métabolisme et Nutrition (ICAN), Paris, France

${ }^{\mathrm{c}} \mathrm{CHU}$ Lille, Endocrinologie, Diabétologie, Métabolisme, Centre de Compétence des Pathologies Rares de l'Insulino-Sécrétion et de l'Insulino-Sensibilité (PRISIS), F-59000, Lille, France

dAssistance Publique-Hôpitaux de Paris (AP-HP), Hôpital Universitaire Robert Debré, Service d'endocrinologie diabétologie pédiatrique, Centre de Compétence des Pathologies Rares de l'Insulino-Sécrétion et de l'Insulino-Sensibilité (PRISIS), F-75019, Paris, France

${ }^{\mathrm{e} U n i v e r s i t e ́ ~ P a r i s ~ D i d e r o t, ~ S o r b o n n e ~ P a r i s ~ C i t e ́, ~ F-75019 ~ P a r i s, ~ F r a n c e ~}$

${ }^{\mathrm{f}}$ Assistance Publique-Hôpitaux de Paris (AP-HP), Hôpital Saint-Antoine, Laboratoire Commun de Biologie et Génétique Moléculaires, F-75012, Paris, France

gSorbonne Université, Inserm, UMR_S933, Hôpital Trousseau, Paris, France

${ }^{\mathrm{h}}$ Assistance publique-Hôpitaux de Paris, Hôpital Universitaire Necker Enfants Malades, Service d'endocrinologie, gynécologie et diabétologie pédiatrique, Centre de Compétence des 
Pathologies Rares de 1'Insulino-Sécrétion et de l'Insulino-Sensibilité (PRISIS), Faculté de médecine Paris Descartes, F-75015, Paris, France

\section{Author for correspondence:}

Camille Vatier

Hôpital Saint-Antoine, Service d'Endocrinologie, Diabétologie et Endocrinologie de la Reproduction, 184, rue du Faubourg Saint-Antoine, 75571 Paris Cedex 12, France

Telephone number: +33171970978

Email address: camille.vatier@aphp.fr

Short title: Monogenic lipodystrophies: clinical cases

Word count: 4562

References: 51

Tables: $\quad 2$

Figures: 3 


\begin{abstract}
Lipodystrophic syndromes are rare diseases of genetic or acquired origin characterized by partial or generalized lack of body fat. Early detection and diagnosis are crucial to prevent and manage associated metabolic dysfunctions, i.e. insulin resistance, dyslipidemia, fatty liver and diabetes, and to provide appropriate genetic counselling. By means of several representative case studies, this article illustrates the diagnostic and management challenges of lipodystrophic syndromes.
\end{abstract}

Berardinelli-Seip congenital lipodystrophy (BSCL) is typically diagnosed at birth, or soon thereafter, with generalized lipoatrophy and hepatomegaly secondary to hepatic steatosis. Physicians must also consider this diagnosis in adults with atypical non-autoimmune diabetes, hypertriglyceridemia and a lean and muscular phenotype. The BSCL1 subtype due to mutations in the $A G P A T 2$ gene can have an unusual presentation, especially in neonates and infants. Particular attention should be paid to infants presenting failure to thrive who also have hepatomegaly and metabolic derangements. The BSCL2 subtype due to mutations in the $B S C L$ gene tends to be more severe than BSCL1, and is characterized by greater fat loss, mild intellectual disability, earlier onset of diabetes, and higher incidence of premature death. Effective management from an earlier age may moderate the natural disease course.

Partial lipodystrophies may easily be confused with common central obesity and/or metabolic syndrome. In patients with unexplained pancreatitis and hypertriglyceridemia, lipodystrophies such as familial partial lipodystrophy type 2 (FPLD2; Dunnigan type, due to $L M N A$ mutations) should be considered. Oral combined contraceptives, which can reveal the disease by inducing severe hypertriglyceridemia, are contraindicated. Endogenous estrogens may also lead to 'unmasking' of the FPLD2 phenotype, which often appears at puberty and is more severe in females than males.

Diet and exercise, adapted to age and potential comorbidities, are essential prerequisites for therapeutic management. Metreleptin therapy can be useful to manage lipodystrophy-related metabolic complications. 
Keywords: Berardinelli-Seip congenital lipodystrophy; familial partial lipodystrophy; congenital generalized lipodystrophy; consanguinity; metreleptin 


\section{Introduction}

Lipodystrophies comprise a group of heterogeneous conditions characterized by a marked decrease, absence and/or redistribution of body fat ${ }^{1}$. In cases of partial fat loss, hypertrophy may occur in other fat depots ${ }^{2}$. Lipodystrophic syndromes are associated with metabolic dysfunction including severe insulin resistance, dyslipidemia, fatty liver and abnormal adipocytokine secretion, all of which lead to early disease complications ${ }^{2,3}$. Several lipodystrophic syndromes are monogenic disorders. Acquired forms of lipodystrophy may also be generalized, or partial, and are often associated with autoimmune diseases ${ }^{4}$. Among them, Barraquer-Simons syndrome is characterized by fat loss in the upper body and fat accumulation in the lower body ${ }^{1,2}$.

Mendelian forms of lipodystrophic syndromes are uncommon and, in several patients, the molecular defect may remain unidentified. Recessive congenital generalized lipodystrophy (also called Berardinelli-Seip congenital lipodystrophy; BSCL) usually arises from pathogenic variants of the $A G P A T 2$ (BSCL1 subtype) or BSCL2 (BSCL2 subtype) genes that encode 1-acyl-glycerol-3-phosphate O-acyltransferase 2 and seipin, respectively ${ }^{5,6}$. Much rarer subtypes involve pathogenic variants of the CAV1 (BSCL3 subtype) and CAVIN1/PTRF (BSCL4 subtype) genes ${ }^{1}$. Conversely, dominant partial familial lipodystrophies, clinical signs of which usually develop around puberty, typically result from molecular defects in $L M N A$, which encodes lamin $\mathrm{A} / \mathrm{C}$, a nuclear protein; or more rarely, from molecular defects in PPARG, which encodes peroxisome proliferator-activated receptor- $\gamma$, an adipogenic transcription factor ${ }^{2}$.

Biochemical, genetic and pathophysiologic studies indicate that lipodystrophic syndromes result mainly from impairment of one or several adipose tissue functions, including adipocyte differentiation, generation and maintenance of adipocyte lipid droplets, and lipid storage ${ }^{2}$. Impaired DNA repair and primary changes in insulin signaling eventually produce specific lipodystrophic phenotypes ${ }^{3}$. 
The causes of acquired lipodystrophy are often unclear. The most frequent forms are localized drug-induced forms, which do not have systemic consequences ${ }^{7}$. Acquired lipodystrophic syndromes associated with metabolic dysfunction may be linked with signs of autoimmunity; however, the most frequent forms are treatment-induced, and associated with chronic corticosteroid administration or some HIV antiretroviral therapies ${ }^{7,8}$. These phenotypes are not discussed in this article.

Diagnosis of lipodystrophy is frequently challenging, and partial forms may easily be confused with common central obesity and metabolic syndrome. Further, in patients with lipodystrophy, glucose and lipid variability is difficult to control, and insulin-sensitizing interventions often fail to adequately control the metabolic alterations; the consequences are early cardiovascular, diabetic, and hepatic complications ${ }^{1-3}$. Diet and exercise, adapted to age and potential comorbidities, are essential prerequisites for therapeutic management ${ }^{4}$. Besides conventional therapies for diabetes and dyslipidemia, leptin replacement is now an approved intervention for the management of metabolic complications in congenital generalized lipodystrophy in the USA, and for both generalized and partial lipodystrophy in Japan ${ }^{4}$. In July 2018, the European Commission granted marketing authorization for metreleptin, as an adjunct to diet, as a replacement therapy to treat the complications of leptin deficiency in adults and children 2 years of age and above with generalized lipodystrophy, and in adults and children 12 years of age and above with partial lipodystrophy for whom standard treatments have failed to achieve adequate metabolic control.

This article focuses on the diagnostic and management challenges in lipodystrophies by highlighting five illustrative case studies - BSCL1 in an elderly patient and in an infant; BSCL2 in two male siblings, each diagnosed within the first few months of life; and p.Arg482Trp $L M N A$-associated lipodystrophy (familial partial lipodystrophy type 2; FPLD2) with hypertriglyceridemia and pancreatitis in a young woman. The article aims to facilitate improved detection, diagnosis, and understanding of these conditions. 


\section{Clinical cases}

\section{Patient 1}

A 70-year-old Caucasian male had generalized lipoatrophic features with hyperphagia since childhood. Diabetes was diagnosed at age 28 years, without any family history of the condition. At the time, the patient's body mass index (BMI) was $20 \mathrm{~kg} / \mathrm{m}^{2}$. At age 55 years, the patient had severe diabetic neuropathy, and incipient nephropathy, and was receiving high doses of insulin (2.5 IU/kg/day) without achieving adequate glucose control; the patient also had marked hypertriglyceridemia (from 6 to $8 \mathrm{mmol} / \mathrm{L}$ ). He presented a spontaneous fracture of the right lateral tibial plateau in the absence of any trauma, with radiographic evidence of an osteolytic lesion. At age 58 years, the patient was treated for non-Hodgkin lymphoma. At age 70 years, he was diagnosed with left carotid artery stenosis.

At presentation, the patient was $1.83 \mathrm{~m}$ tall, had a bodyweight of $67 \mathrm{~kg}$, and had generalized lipoatrophy, moderate muscular hypertrophy, very low fat mass (4.2\%) assessed by dualenergy x-ray absorptiometry (DEXA), and a very low serum leptin level $(0.34 \mathrm{ng} / \mathrm{mL})$. There was no evidence of auto-immune disorders and investigation for serum autoantibodies was negative. He reported that his parents were first cousins. The patient's glycated hemoglobin (HbA1c) level was $8.3 \%$, despite receiving high dose insulin therapy (2.7 IU/kg/day) and metformin $3 \mathrm{~g} /$ day. Triglycerides were increased (5.29 $\mathrm{mmol} / \mathrm{L})$ and high-density lipoprotein cholesterol was decreased $(0.78 \mathrm{mmol} / \mathrm{L})$. Incipient nephropathy was confirmed with microalbuminuria at $8.4 \mathrm{mg} / \mathrm{mmol}$, and an estimated creatinine clearance (Modification of Diet in Renal Disease) of $83 \mathrm{~mL} / \mathrm{min}$. Whole-body bone radiographs revealed diffuse osteosclerosis and several osteolytic lesions of long bones ${ }^{9}$.

The association of generalized lipoatrophy, atypical diabetes with severe insulin resistance, hypertriglyceridemia, bone lesions, and parental consanguinity suggested a diagnosis of BSCL. Sequencing of $A G P A T 2$ confirmed the diagnosis of BSCL1 by revealing a pathogenic homozygous p.Glu172Lys variant. 
Metreleptin (Myalept ${ }^{\circledR}$; Aegerion Pharmaceuticals Inc., Cambridge, MA, USA) was added to the patient's insulin and metformin treatment. Metreleptin was started at a dosage of 0.02 $\mathrm{mg} / \mathrm{kg} /$ day administered subcutaneously, increased to $0.08 \mathrm{mg} / \mathrm{kg} /$ day after $1 \mathrm{month}$, and adapted to metabolic results at a dosage of $0.11 \mathrm{mg} / \mathrm{kg} /$ day thereafter. The patient selfadministered the injection as one daily dose. Marked decreases in HbAlc, fasting blood glucose, and triglycerides were soon observed (Figure 1), as was reversal of microalbuminuria. The daily insulin requirement decreased from $2.5 \mathrm{IU} / \mathrm{kg}$ to $2.1 \mathrm{IU} / \mathrm{kg}$. Treatment adherence was good, as assessed by the Girerd questionnaire ${ }^{10}$, as were tolerability and satisfaction with treatment, self-evaluated by the patient via the Treatment Satisfaction Questionnaire for Medication version $\mathrm{II}^{11}$ : global satisfaction was $83 \%$, efficiency $75 \%$, and comfort of use $55 \%$. A high score for secondary effects (100\%) was related to local pain after injection, but this was the only side effect and was tolerable. Metabolic control of the disease was sustained after more than 3 years of therapy.

\section{Patient 2}

A 6-month-old male patient was admitted to an intensive care unit with lactic acidosis and painful hepatomegaly. He also had diarrhea, failure to thrive, malnutrition, edema, and asthenia. He was born full term and had no medical history. His parents were consanguineous and originated from Senegal. He had two older, healthy sisters.

Initially, the patient had been hospitalized in the gastroenterology department, but was transferred to the intensive care unit (ICU) because of superficial polypnea caused by hyperalgesic hepatomegaly. Blood tests revealed severe hypoalbuminemia ( $22.4 \mathrm{~g} / \mathrm{L})$, hepatic cytolysis (maximum aspartate transaminase [AST] 227 IU/L; alanine transaminase [ALT] $219 \mathrm{IU} / \mathrm{L}$ ), hemostasis disorders (minimum prothrombin time 53\%), hypertriglyceridemia (maximum $23.3 \mathrm{mmol} / \mathrm{L}$ ), hypercholesterolemia (maximum $5.73 \mathrm{mmol} / \mathrm{L}$ ), microcytic anemia (minimum hemoglobin $6.9 \mathrm{~g} / \mathrm{dL}$; mean corpuscular volume $71.9 \mu \mathrm{m}^{3}$ ), and lactic acidosis ( $\mathrm{pH} 7.30 ; \mathrm{pCO}_{2} 28 \mathrm{mmHg}$; bicarbonate $14 \mathrm{mmol} / \mathrm{L}$; lactate $7 \mathrm{mmol} / \mathrm{L}$ ). 
Symptomatic treatment was started with red blood cell transfusion, analgesic treatment with morphine and ketamine, low fat enteral nutrition (Monogen ${ }^{\circledR}$; Nutricia Nutrition Clinique SAS, Paris, France) and parenteral nutrition. During parenteral nutrition, the patient developed insulin-resistant diabetes (fasting blood glucose $7.7 \mathrm{mmol} / \mathrm{L}$; fasting insulin 254 mIU/L; homeostasis model assessment of insulin resistance [HOMA-IR] 87). However, low fat nutrition led to major metabolic improvements (Table 1).

Considering the patient's symptom constellation of failure to thrive, hepatomegaly, lactic acidosis, and major hypertriglyceridemia, an inborn error of metabolism was initially suspected, but all metabolic tests were negative. Ileocoloscopy was normal, but liver biopsies revealed diffuse steatosis. Clinicians then noted a lipodystrophy (Figure 2) which led to suspicion of BSCL. The diagnosis of BSCL1 was confirmed by identification of a homozygous splice-site mutation in the AGPAT2 gene. This recurrent c.589-2A $>\mathrm{G} A G P A T 2$ pathogenic variant results in synthesis of an aberrant and truncated AGPAT2 protein (p.Gln196fs*228) $)^{5,12}$. After genetic confirmation of the BSCL1 diagnosis, the low-fat diet was switched to medium-chain triglycerides (Lipistart ${ }^{\circledR}$; Nestlé Health Science, Marne-laVallée, France). Parenteral nutrition was stopped after 1 month when the patient had regained weight. Enteral nutrition could not be stopped due to oral feeding difficulties. Fasting blood glucose gradually returned to the normal range upon discontinuation of parenteral nutrition. At the last visit, the patient was aged 1 year, and blood tests (hepatic and hemostatic function; glycemia; insulinemia; triglycerides) were normal with a diet enriched in medium-chain triglycerides.

\section{Patients 3 and 4}

Patients 3 and 4 were brothers, each diagnosed with BSCL in their first months of life, which was further shown to be due to a homozygous p.Arg138Stop BSCL2 pathogenic variant transmitted from consanguineous parents ${ }^{7}$. The siblings entered a 4-month open-label trial of metreleptin therapy at 7 and 11 years old, respectively. At that time, their endogenous leptin 
levels were very low at 1.2 and $0.6 \mathrm{ng} / \mathrm{mL}$, respectively. Metabolic abnormalities consisted of hypertriglyceridemia (2.74 and $5.25 \mathrm{mmol} / \mathrm{L}$, respectively), liver steatosis with slightly increased ALT (66 and $73 \mathrm{IU} / \mathrm{L}$, respectively), and insulin resistance with normal glucose tolerance.

After 4 months' treatment with metreleptin, administered at increasing doses up to 0.06 $\mathrm{mg} / \mathrm{kg} /$ day, improvements were observed in triglycerides (reaching 0.61 and $4.16 \mathrm{mmol} / \mathrm{L}$, respectively) and liver enzymes (return to normal values in both patients). The response to metreleptin was more pronounced in the younger brother, who also showed striking improvement in his insulin sensitivity. These results were reported in 2007 with Patients 3 and 4 being referred to as Patients 5 and 6, respectively ${ }^{13}$.

Although metreleptin treatment was withdrawn after the trial, the brothers were later able to benefit from long-term compassionate use of metreleptin, at ages 9 and 13 years, respectively. Prior to the start of treatment, serum triglycerides were 3.5 and $4.0 \mathrm{mmol} / \mathrm{L}$, respectively. HbA1c and fasting glucose levels were normal although fasting insulin levels were very high at 238 and $340 \mathrm{pmol} / \mathrm{L}$, respectively. Both brothers presented hepatomegaly and increased ALT (66 mIU/L in each child). After 28 months of metreleptin treatment, administered at a dose of 0.09 to $0.12 \mathrm{mg} / \mathrm{kg} /$ day, triglycerides, insulin sensitivity, and hepatic volume improved in the younger brother, whereas only ALT levels decreased significantly in the older brother. These results were reported in 2010 with Patients 3 and 4 being referred to as Patients 7 and 1 , respectively ${ }^{14}$.

At the time of evaluation in the adult endocrinology department, the brothers were aged 18 and 22 years, respectively. They had received metreleptin for nine years without interruption, at a dose of $0.08 \mathrm{mg} / \mathrm{kg} / \mathrm{day}$ and $0.12 \mathrm{mg} / \mathrm{kg} /$ day, respectively, with excellent observance and tolerance. Each sibling had generalized lipoatrophy with pseudoacromegaloid appearance, muscular hypertrophy and moderate acanthosis nigricans. Both had achieved normal growth and pubertal development. BMIs were 22.3 and $23.6 \mathrm{~kg} / \mathrm{m}^{2}$, respectively. Although cognitive function was slightly altered, both men were able to work as employees. Hepatomegaly and 
scoliosis were present in each sibling, more severely in Patient 4, who also had recurrent urinary tract infections, and recurrent skin abscesses complicating severe acne. Metformin had been added to therapy at ages 16 and 20 years, respectively, leading to further improvement in acanthosis nigricans.

Fasting glucose and HbA1c levels had remained normal since childhood, with values of 4.7 $\mathrm{mmol} / \mathrm{L}$ and $5.3 \%$ (Patient 3 ) and $4.5 \mathrm{mmol} / \mathrm{L}$ and $5 \%$ (Patient 4). Serum triglycerides were slightly elevated $(2.2 \mathrm{mmol} / \mathrm{L})$ in Patient 3 without lipid-lowering therapy, and were wellcontrolled under fenofibrate therapy in Patient $4(1.8 \mathrm{mmol} / \mathrm{L})$ in whom hypertriglyceridemia had reached a maximum of $6.8 \mathrm{mmol} / \mathrm{L}$ at age 20 years. Liver enzymes were normal in both patients.

The siblings were both diagnosed with hypertrophic cardiomyopathy at echography, at age 16 (Patient 3) and 20 (Patient 4) years, leading to initiation of angiotensin-converting enzyme (ACE) inhibitor therapy. In Patient 4, moderately increased hypertension and microalbuminuria were well controlled by treatment. Cardiac function was normal without rhythm disturbances in either patient. Renal function was normal.

During follow-up, Patient 4 was treated successfully at age 22 with a 6-month course of isotretinoin, which he tolerated well with no recurrence of furunculosis or acne up to his current age of 26 years. He also underwent successful corrective orthopedic surgery for scoliosis at age 23 years.

At ages 22 and 26 years, respectively, Patients 3 and 4 continue to receive metreleptin, metformin and ACE inhibitors, associated with fenofibrate in Patient 4. Their general condition is good, and metabolic parameters are stable without hyperglycemia and hypertriglyceridemia. Liver enzymes are normal, with the exception of elevated ALT (58 IU/L) in Patient 4.

\section{Patient 5}


A 19-year-old woman was admitted to the emergency department with coma related to inaugural diabetic ketoacidosis. Unlike most cases of ketoacidosis, the patient was in a deep coma despite $\mathrm{pH} 7.09$, and had cutaneous xanthomatosis. The patient had a family history of type 2 diabetes with obesity (father); and hypertension and dyslipidemia (without obesity), with subsequent diabetes (mother). No other family members had diabetes, and there was no consanguinity in the family.

At presentation, the patient was lean with no neurologic signs of focalization, despite coma. She had severe hirsutism and abdominal guarding. Her BMI was $19.9 \mathrm{~kg} / \mathrm{m}^{2}$, and her blood pressure was 120/70 mm Hg. Ketoacidosis was biologically confirmed with ketonuria, and a high lipase level suggested acute pancreatitis. Laboratory values were: serum bicarbonate 3.6 $\mathrm{mmol} / \mathrm{L}$, blood glucose $17.2 \mathrm{mmol} / \mathrm{L}$, triglycerides $160 \mathrm{mmol} / \mathrm{L}, \gamma$-glutamyl transferase 158 $\mathrm{mmol} / \mathrm{L}$, ALT $60 \mathrm{IU} / \mathrm{mL}$, and AST $127 \mathrm{IU} / \mathrm{mL}$. The patient spent several days in the ICU. Despite improved metabolic status during insulin therapy and rehydration, persistent abdominal guarding was obvious. Surgical exploration revealed necrotic pancreatitis, hepatic steatosis, and an enlarged left adrenal gland, which was removed, because of severe hirsutism and suspicion of tumor. Cholecystectomy was performed at the same time. The ovaries were enlarged, smooth and regular, and liver biopsy confirmed major diffuse steatosis. Histologic analysis of the adrenal gland revealed no tumor.

The patient was strikingly virilized (Ferriman and Gallway score 26), with muscular hypertrophy. A larger biacromial than bitrochanteric diameter was noticed (48 vs $38 \mathrm{~cm})$. Mild acne, temporal hair recession, and acanthosis nigricans on the vulvae and inner thigh were present. The patient had minimal subcutaneous fat on the body and limbs, with a bicipital skin fold thickness of $2 \mathrm{~mm}$ (normal $<25 \mathrm{~mm}$ ), small breasts, and only $14.6 \%$ of whole body fat (measured later by DEXA).

Subsequently, we learned that non-insulin-dependent diabetes and hyperlipidemia (fasting blood glucose $11 \mathrm{mmol} / \mathrm{L}$; total cholesterol $7.53 \mathrm{mmol} / \mathrm{L}$; triglycerides $4.62 \mathrm{mmol} / \mathrm{L}$ ) had been discovered at age 16 years, with irregular menses (every 4-5 months) since menarche at 
age 12 years, and severe hirsutism requiring daily shaving. The patient had been treated with diet and fenofibrate. A few months prior to the episode of ketoacidosis, an anti-androgenic contraceptive pill (ethinylestradiol $35 \mu \mathrm{g}$ plus cyproterone acetate $2 \mathrm{mg}$ ) had been prescribed. Fasting blood samples at a time distant from the ketoacidotic episode later confirmed insulin resistance (blood glucose $8.7 \mathrm{mmol} / \mathrm{L}$; insulin $34 \mathrm{mIU} / \mathrm{L}$; C-peptide $4.36 \mathrm{ng} / \mathrm{mL}$ ). Thus, the diagnosis of ketoacidosis related to severe insulin-resistant lipodystrophic diabetes, exacerbated by contraceptive pill prescription, together with induced pancreatitis, was corroborated.

After the acute episode of diabetic ketoacidosis, the oral contraceptive pill was stopped and the patient was treated with a normocaloric normolipidic diet, with carbohydrates $180 \mathrm{~g} / \mathrm{day}$. Insulin was administered subcutaneously, first via syringe and then via an external pump, followed by intravenous administration via an external pump. Subsequently, insulin was administered intraperitoneally, using an implanted pump (Minimed MMT 2001; Medtronic France SAS, Paris, France), for more than 5 years. Subcutaneous insulin delivery provided poor metabolic results, and the external pump led to repeated subcutaneous abscess formation. The patient's menses remained irregular, but she had no hypoglycemic episodes. Table 2 shows the patient's long-term metabolic and hormonal results during insulin therapy. $\mathrm{HbA} 1 \mathrm{c}$ remained at about $10 \%$, but dyslipidemia tended to worsen over time. Metformin (3 $\mathrm{g}$ /day) added to insulin improved the consistency of menses (every 2 months), hirsutism, and plasma testosterone and sex hormone-binding globulin levels, but with no improvement in HbA1c and dyslipidemia. Subsequently, a satisfying metabolic balance was attained when subcutaneous insulin was administered via a high-output pump (4 IU/kg/day), likely in conjunction with better follow-up of lifestyle recommendations. Despite HbA1c levels being maintained at around $7 \%$, retinopathy and neuropathy occurred, probably due to prior poor glycemic balance.

In 2000, when the patient was aged 32 years, her plasma leptin level was well below the normal range (1.51 ng/mL; normal values 3.7-11.1). A p.Arg482Trp LMNA heterozygous pathogenic variant was identified in the patient, her mother, and brother ${ }^{15}$, thus leading to a 
diagnosis of FPLD2. Metreleptin therapy was started at the time it became available (i.e. when the patient was aged 41 years) with associated improvement in metabolic parameters during the first year of treatment (Figure 3). Overt decreases in the faciocervical fat depot and insulin resistance permitted discontinuation of insulin-pump therapy. Lower-dose, longacting, injectable insulin plus metformin was continued. The patient tolerated metreleptin well and was particularly satisfied with treatment compared with insulin-pump therapy, and with the improvement in hirsutism. No adverse effects to metreleptin occurred during more than 3 years' administration. The treatment did not reverse the microalbuminuria (around 150 $\mathrm{mg} / \mathrm{L}$ ) which had occurred over time.

\section{Discussion}

The principal goals of this article are to facilitate early and differential diagnosis of lipodystrophies, and to improve the understanding and treatment of these conditions. Five illustrative case studies - two cases of BSCL1 (one in an elderly male [Patient 1] and one in an infant [Patient 2]), two cases of BSCL2 in young men (Patients 3 and 4); and one case of LMNA mutation-positive lipodystrophy in a young woman (Patient 5) - are presented to support these goals.

\section{Congenital generalized lipodystrophy}

BSCL is typically diagnosed at birth, or soon thereafter, with generalized lipoatrophy and hepatomegaly secondary to hepatic steatosis. As functional adipocytes are absent, lipids become stored in other tissues, such as skeletal muscle and liver which leads to an array of complications. Insulin resistance manifests in affected individuals, approximately $25-35 \%$ of whom develop diabetes when aged 15-20 years ${ }^{16}$, and almost all of whom develop hepatomegaly secondary to steatosis, together with skeletal muscle hypertrophy. Approximately $20-25 \%$ of patients with BSCL develop hypertrophic cardiomyopathy, which 
is a major cause of morbidity due to heart failure, especially in BSCL2 ${ }^{16}$. Indeed, BSCL2 is usually more severe than BSCL1, with more severe and precocious lack of fat, lower serum leptin level, earlier onset of diabetes, higher prevalence of mild intellectual disability, and higher incidence of premature death ${ }^{16-19}$.

Diagnosis of BSCL is particularly important so that lifestyle interventions can be adopted from an early age to prevent metabolic complications ${ }^{4,20}$. Subsequent treatment of complications can be adapted to meet specific patient needs; and appropriate genetic counselling can be provided ${ }^{21}$. However, some phenotypes are initially less severe than others and diagnosis may be delayed (e.g. Patient 1).

Leptin deficiency, associated with reduced amounts of fat, is considered to contribute to the metabolic complications associated with lipodystrophic syndromes, as shown in murine studies $^{22,23}$ and human trials ${ }^{24,25}$. In generalized lipodystrophies, and to a lesser extent in partial lipodystrophies, treatment with metreleptin was associated with a markedly reduced hepatic and muscular lipid content, and improved insulin sensitivity, insulin secretion, hyperglycemia, and dyslipidemia, in part independently of reduced caloric intake ${ }^{24-27}$. Thus, metreleptin is now approved in the US and $\mathrm{Japan}^{4}$, and has conditional marketing authorization in Europe, as an adjunct to diet for treatment of metabolic complications in patients with congenital generalized lipodystrophy.

In the case of Patient 1, the atypical presentation of diabetes in a young lean patient (28 years at the time of diagnosis), without a family history of diabetes and without type 1 diabetes autoantibodies, but with a clinical phenotype of generalized lipoatrophy, suggested the need for genetic analysis for lipodystrophic syndromes; this was even more pertinent in the context of consanguinity. To confirm the lipoatrophic phenotype, measurement of leptinemia, and fat mass by DEXA, were important and also provided a good indication of lipoatrophy severity. In this case, the antecedent of lymphoma could raise the question of acquired generalized lipodystrophy. Indeed, coexistence of lymphoma and acquired generalized lipodystrophy has been reported, and likely relates to underlying autoimmunity in both conditions ${ }^{28}$. However, 
as there was no evidence of autoimmune disorders in the patient, the search for a genetic cause of lipodystrophic syndrome was mandatory. The late diagnosis of congenital generalized lipodystrophy led to delayed introduction of metreleptin therapy at 71 years of age. However, the association of metreleptin, high-dose insulin, and metformin remained effective for long-term control of the metabolic abnormalities. Overall, Patient 1 highlights the importance of a thorough physical examination, particularly regarding adipose tissue repartition. Further, an atypical presentation of diabetes should proceed well beyond identification of diabetes type. Physicians must consider lipodystrophic syndromes when diabetes is associated with hypertriglyceridemia and a lean and muscular phenotype. The possibility of parental consanguinity should also be considered to increase the likelihood of diagnosis.

Patient 2 also presented with BSCL, a rare disease with a reported prevalence of 0.01 to 4 per 100000 , depending on the world region ${ }^{29}$. The patient, who had the BSCL1 subtype, was initially referred to hospital for diarrhea and failure to thrive, which are unusual symptoms in the diagnosis of congenital generalized lipodystrophy. Van Maldergem et al. described 17 patients with BSCL1, of whom 11 had their condition diagnosed before age 1 year ${ }^{16}$. Only one patient had failure to thrive, but without diarrhea. Seven patients were referred for lipoatrophy (with a family history in two cases) and two for hepatomegaly.

A few years ago, another patient presented to the gastroenterology department of the Robert Debré Hospital with BSCL1 due to AGPAT2 compound heterozygous pathogenic variants. At just 3 weeks of age, this patient had the same symptoms as were observed in the current case. After developing severe diabetes mellitus and being treated with parenteral nutrition, the outcome was successful: at discharge, the patient was normoglycemic without insulin treatment. BSCL1 due to mutations in AGPAT2 appears to be more frequent in patients of African descent ${ }^{4}$, which was the case for both of these young patients.

Although rarely described in the literature, failure to thrive and diarrhea were the main symptoms that enabled discovery of congenital generalized lipodystrophy in these two 
patients. Particular attention should be paid to patients presenting with these symptoms who also have hepatomegaly or metabolic disorders; lipodystrophy should be considered in the differential diagnosis. Administration of intravenous glucose confirmed the presence of insulin-resistant diabetes in both patients, as was also described in a previous case report ${ }^{30}$. However, insulin resistance declined strongly when the patients resumed feeding. Our observations also emphasize the importance of a controlled diet for managing BSCL. The eucaloric diet of our patient was enriched with medium-chain triglycerides, which may have contributed to resolving the metabolic derangements, as previously reported ${ }^{4,31,32}$. Additionally, adjusting the diet to reference daily intake is also of major importance to improve metabolic parameters in children with BSCL, as recently reported ${ }^{20}$.

Patients 3 and 4 were diagnosed with BSCL2, which is reported to be more severe than BSCL1 as discussed above ${ }^{16-18}$. The disease course was milder than expected, however. Under treatment, the siblings had no signs of hyperglycemia or hypertriglyceridemia at age 22 and 26 years, respectively. Although it could not be demonstrated, it is plausible that early treatment with metreleptin played a role in this favorable evolution.

\section{Familial partial lipodystrophy type 2 (FPLD2)}

Lipodystrophies are rare diseases and the diagnosis is often overlooked ${ }^{33}$. LMNA-related lipodystrophy characteristics (e.g. generalized or partial fat atrophy with metabolic changes and insulin resistance) may be due to altered differentiation of adipocytes or changed fat structure $^{34}$. The principal feature of FPLD2 is loss of fat, commencing at about pubertal age in women, in the buttocks, hips, limbs, and trunk, together with accumulation of fat in the axillae, back, face, labia majora, and visceral region. This distribution of fat, coupled with enhanced and well-defined musculature, means that affected women take on an android appearance. Further, phlebomegaly is often present in the upper and lower limbs, and the hands tend to be broad with small digits. Acanthosis nigricans in the axillae and neck and acrochordons, as signs of insulin resistance, are not infrequent. Women with FPLD2 
frequently present with gynecologic disorders such as gestational diabetes, miscarriage, polycystic ovarian syndrome, and stillbirth ${ }^{35}$. In men, the abovementioned fat-loss changes occur later and are less evident; indeed, men with FPLD2 are typically diagnosed from female kin. Although subcutaneous lipomas are not present in all cases ${ }^{36}$, their presence should make physicians suspect FPLD2 when a background FPLD phenotype exists. The cardiovascular diversity of FPLD2 is broad and includes early atherosclerotic disease, arrhythmias, hypertrophic cardiomyopathy, and valvulopathies. Atherosclerotic disease and metabolic disturbances are less frequent in men than women with FPLD2 ${ }^{37}$.

Pancreatitis has been reported in different types of metabolic syndrome, either acquired mainly related to corticosteroid use $\mathrm{e}^{38-40}$ or inherited, and especially in lipodystrophic syndromes $^{41-48}$. Nevertheless, all FPLD2 patients do not have recurrent pancreatitis, and other environmental or genetic factors may be involved (especially the intensity of leptin deficiency) that may vary across the different types of lipodystrophy ${ }^{49-51}$.

Synthetic estrogens are known causes of dyslipidemia, and prescription of the contraceptive pill in Patient 3 was clearly inappropriate. Indeed, estrogens may lead to 'unmasking' of FPLD2, which often appears at puberty and is more severe in females than males ${ }^{15}$; this raises questions about the pathogenetic role of steroid hormones in this disease phenotype.

Diagnostic challenges existed for Patient 3 in that ketoacidosis related to insulinopenic type 1 diabetes complicated with hypertriglyceridemia, which may predispose to pancreatitis, was initially suspected. However, pancreatitis per se may also lead to ketoacidosis, and high triglyceride levels can also result from excess levels of steroid hormones (including sex hormones) and a history of misuse of hormonal therapy. In this case, the high fasting level of C-peptide $(4.36 \mathrm{ng} / \mathrm{mL})$, without pancreatic antibodies, was not concordant with type 1 diabetes. Severe hirsutism, spaniomenorrhea, hypertriglyceridemia, and high C-peptide level were highly suggestive of insulin resistance. Further, the patient was lean, had no history of alcohol consumption, and no pancreatic duct lithiasis, yet pancreatitis and hypertriglyceridemia were much more severe than typically observed in ketoacidosis. In addition, muscular hypertrophy, peripheral lipoatrophy, hypotrophic breasts, and severe 
hirsutism were suggestive of FPLD2. Type A insulin resistance syndrome was initially suspected due to severe hyperandrogenism, but no mutation of the insulin receptor was found. Overall, the metabolic phenotype, complicated by hypertriglyceridemia and pancreatitis during contraceptive administration, was explained by a pathogenic variant in $L M N A$, which was identified when the genetic basis of lipodystrophies became better defined.

\section{Conclusions}

Because lipodystrophic syndromes are rare, many physicians are inexperienced in the diagnosis and management of these disorders. Specific, additional diagnostic efforts are thus required in patients presenting with atypical diabetes. A thorough physical examination for fat mass repartition, muscular phenotype, and hepatomegaly, is necessary. Standard metabolic exploration for hepatic enzyme levels, hypertriglyceridemia, and insulinemia, is also necessary, as is fat mass assessment by DEXA, and evaluation for leptinemia. BSCL can have an unusual presentation, especially in neonates and infants. The symptoms can easily be confused with other metabolic disorders. Although lipodystrophic syndromes are rare, early diagnosis is imperative to facilitate specific management. Metreleptin can be helpful, in addition to diet and other antidiabetic medications, to efficiently control the metabolic complications of congenital generalized lipodystrophy.

If lipodystrophic or insulin-resistant phenotypes are present, blood glucose and lipid levels should be checked carefully before first prescription of a combined contraceptive pill. In patients with unexplained pancreatitis and hypertriglyceridemia, lipodystrophies such as FPLD2 (Dunnigan type) should be considered.

\section{Transparency}




\section{Declaration of funding}

Aegerion Pharmaceuticals, Cambridge, MA, USA, the manufacturer of metreleptin $\left(\right.$ Myalept $\left.^{\circledR}\right)$, provided financial assistance through an unrestricted educational program for presentation of clinical cases in this article.

\section{Declaration of financial/other relationships}

Camille Vatier has received personal fees for consultancy, travel, or accommodation from Aegerion Pharmaceuticals, Lilly, Novo Nordisk, Sanofi, Servier, and Vitalaire.

Marie-Christine Vantyghem was invited by Aegerion for a conference on lipodystrophies at the Endodiabetes 2018 meeting (transportation and accommodation, with no other fee).

Caroline Storey has received personal fees for travel or accommodation from IPSEN and Sanofi.

Bruno Fève has received personal fees for consultancy, lecture, travel, or accommodation by Merck Sharp \& Dohme, Novo Nordisk, Sanofi, and institutional research grants from ViivHealthcare and Merck Sharp \& Dohme.

Corinne Vigouroux has received personal fees for consultancy, lecture, travel, or accommodation from Aegerion Pharmaceuticals, Air Products, AstraZeneca, Boehringer Ingelheim, Bristol-Myers Squibb, Gilead, Jansen-Cilag, Merck-Serono, Novo Nordisk, Orkyn, Sanofi, Servier, Viiv-Healthcare, and Vitalaire, and institutional research grants from Pierre-Fabre Médicament, Roche Diagnostics and Servier.

Elise Bismuth has received personal fees for consultancy, lecture, travel, or accommodation from Eli Lilly, Abbott Diabetes Care, and Medtronic.

Other authors did not declare any conflicts of interest. 


\section{Author contributions}

C.Va., M-C.V., C.S., J-C.C, C.Vi and E.B. were involved in the writing of the clinical cases, discussion and conclusion. C.Va., M-C.V., C.S., S.C-M, B.F., J.B., J-C.C, C.Vi and E.B. contributed to patient care. I.J., O.L. and C.Vi. were involved in genetic analyses. All authors reviewed and approved the final article.

\section{Acknowledgments}

The authors acknowledge the patients, the healthcare professionals at Saint-Antoine Hospital, Endocrinology and Molecular Biology Departments, and Robert Debré Hospital, Pediatric Endocrinology Department, and Assistance Publique-Hôpitaux de Paris and Lille University Hospital, Endocrinology Department; Dr Sylvie Falcon-Eicher and Profs Frédéric Huet, JeanFrançois Gautier and Bruno Vergès who contributed to the medical care of Patients 3 and 4; Amylin, Bristol-Myers Squibb, and AstraZeneca; and Aegerion, who provided metreleptin.

Writing assistance, provided by Content Ed Net (Basel, Switzerland) with funding from Aegerion, was used in production of this manuscript. 


\section{References}

1. Hussain I, Garg A. Lipodystrophy syndromes. Endocrinol Metab Clin North Am 2016;45:783-97.

2. Vatier C, Bidault G, Briand N, et al. What the genetics of lipodystrophy can teach us about insulin resistance and diabetes. Curr Diab Rep 2013;13:757-67.

3. Melvin A, O'Rahilly S, Savage DB. Genetic syndromes of severe insulin resistance. Curr Opin Genet Dev 2018;50:60-7.

4. Brown RJ, Araujo-Vilar D, Cheung PT, et al. The diagnosis and management of lipodystrophy syndromes: A multi-society practice guideline. J Clin Endocrinol Metab 2016;101:4500-11.

5. Agarwal AK, Arioglu E, De Almeida S, et al. AGPAT2 is mutated in congenital generalized lipodystrophy linked to chromosome 9q34. Nat Genet 2002;31:21-3.

6. Magré J, Delépine M, Khallouf E, et al. Identification of the gene altered in Berardinelli-Seip congential lipodystrophy on chromosome 11q13. Nat Genet $2001 ; 28: 365-70$.

7. Nolis T. Exploring the pathophysiology behind the more common genetic and acquired lipodystrophies. J Hum Genet 2014;59:16-23.

8. Caron-Debarle M, Lagathu C, Boccara F, et al. HIV-associated lipodystrophy: from fat injury to premature aging. Trends Mol Med 2010;16:218-29.

9. Teboul-Coré S, Rey-Jouvin C, Miguel A, et al. Bone imaging findings in genetic and acquired lipodystrophic syndromes: an imaging study of 24 cases. Skeletal Radiol 2016;45:1495-506. 
10. Girerd X, Hanon O, Anagnostopoulos K, et al. Assessment of antihypertensive compliance using a self-administered questionnaire: development and use in a hypertension clinic. Presse Med 2001;30:1044-8 [article in French].

11. Atkinson MJ, Kumar R, Cappelleri JC, Hass SL. Hierarchical construct validity of the treatment satisfaction questionnaire for medication (TSQM version II) among outpatient pharmacy consumers. Value Health 2005;8 Suppl 1:S29-S24. 12.

12. Magré J, Delépine M, Van Maldergem L, et al. Prevalence of mutations in AGPAT2 among human lipodystrophies. Diabetes 2003;52:1573-8.

13. Beltrand J, Beregszaszi M, Chevenne D, et al. Metabolic correction induced by leptin replacement treatment in young children with Berardinelli-Seip congenital lipoatrophy. Pediatrics 2007;120:e291-6.

14. Beltrand J, Lahlou N, Le Charpentier T, et al. Resistance to leptin-replacement therapy in Berardinelli-Seip congenital lipodystrophy: an immunological origin. Eur J Endocrinol 2010;162:1083-91.

15. Vigouroux C, Magre J, Vantyghem MC, et al. Lamin A/C gene: sex-determined expression of mutations in Dunnigan-type familial partial lipodystrophy and absence of coding mutations in congenital and acquired generalized lipoatrophy. Diabetes 2000;49:1958-62.

16. Van Maldergem L, Magre J, Khallouf TE, et al. Genotype-phenotype relationships in Berardinelli-Seip congenital lipodystrophy. J Med Genet 2002;39:722-33.

17. Simha V, Garg A. Phenotypic heterogeneity in body fat distribution in patients with congenital generalized lipodystrophy caused by mutations in the AGPAT2 or seipin genes. J Clin Endocrinol Metab 2003;88:5433-7.

18. Agarwal AK, Simha V, Oral EA, et al. Phenotypic and genetic heterogeneity in congenital generalized lipodystrophy. J Clin Endocrinol Metab 2003;88:4840-7. 
19. Lima JG, Nobrega LHC, Lima NN, et al. Causes of death in patients with Berardinelli-Seip congenital generalized lipodystrophy. PLoS One 2018;13:e0199052.

20. Papendieck L, Araujo MB. Clinical outcome in a series of pediatric patients with congenital generalized lipodystrophies treated with dietary therapy. J Pediatr Endocrinol Metab 2018;31:77-83.

21. Jeru I, Vatier C, Araujo-Vilar D, et al. Clinical utility gene card for: congenital generalized lipodystrophy. Eur J Hum Genet 2016;24(11).

22. Shimomura I, Hammer RE, Ikemoto S, et al. Leptin reverses insulin resistance and diabetes mellitus in mice with congenital lipodystrophy. Nature 1999;401:73-6.

23. Colombo C, Cutson JJ, Yamauchi T, et al. Transplantation of adipose tissue lacking leptin is unable to reverse the metabolic abnormalities associated with lipoatrophy. Diabetes 2002;51:2727-33.

24. Javor ED, Cochran EK, Musso C, et al. Long-term efficacy of leptin replacement in patients with generalized lipodystrophy. Diabetes 2005;54:1994-2002.

25. Chong AY, Lupsa BC, Cochran EK, Gorden P. Efficacy of leptin therapy in the different forms of human lipodystrophy. Diabetologia 2010;53:27-35.

26. Diker-Cohen T, Cochran E, Gorden P, Brown RJ. Partial and generalized lipodystrophy: comparison of baseline characteristics and response to metreleptin. J Clin Endocrinol Metab 2015;100:1802-10.

27. Vatier C, Fetita S, Boudou P, et al. One-year metreleptin improves insulin secretion in patients with diabetes linked to genetic lipodystrophic syndromes. Diabetes Obes Metab 2016;18:693-7.

28. Brown RJ, Chan JL, Jaffe ES, et al. Lymphoma in acquired generalized lipodystrophy. Leuk Lymphoma 2016;57:45-50. 
29. de Azevedo Medeiros LB, Cândido Dantas VK, Craveiro Sarmento AS, et al. High prevalence of Berardinelli-Seip Congenital Lipodystrophy in Rio Grande do Norte State, Northeast Brazil. Diabetol Metab Syndr 2017;9:80.

30. Mora PF, Ramirez LC, Lender D, Raskin P. Insulin requirements in lipodystrophic diabetes. Diabet Med 1993;10:863-5.

31. Lee IH, Chen HL, Jeng YM, et al. Congenital generalized lipodystrophy in a 4month-old infant. J Formos Med Assoc 2001;100:623-7.

32. Montenegro RM Jr, Montenegro AP, Fernandes MI, et al. Triglyceride-induced diabetes mellitus in congenital generalized lipodystrophy. J Pediatr Endocrinol Metab $2002 ; 15: 441-7$.

33. Vantyghem MC, Balavoine AS, Douillard C, et al. How to diagnose a lipodystrophy syndrome. Ann Endocrinol (Paris) 2012;73:170-89.

34. Vigouroux C, Guénantin A-C, Vatier C, et al. Lipodystrophic syndromes due to LMNA mutations: recent developments on biomolecular aspects, pathophysiological hypotheses and therapeutic perspectives. Nucleus 2018;9:235-48.

35. Vantyghem MC, Vincent-Desplanques D, Defrance-Faivre F, et al. Fertility and obstetrical complications in women with LMNA-related familial partial lipodystrophy. J Clin Endocrinol Metab 2008;93:2223-9.

36. Araújo-Vilar D, Victoria B, González-Méndez B, et al. Histological and molecular features of lipomatous and nonlipomatous adipose tissue in familial partial lipodystrophy caused by LMNA mutations. Clin Endocrinol (Oxf) 2012;76:816-24.

37. Guillín-Amarelle C, Fernández-Pombo A, Sánchez-Iglesias S, Araújo-Vilar D. Lipodystrophic laminopathies: Diagnostic clues. Nucleus 2018;9):249-60. 
38. Fardet L, Kassar A, Cabane J, Flahault A. Corticosteroid-induced adverse events in adults: frequency, screening and prevention. Drug Saf 2007;30:861-81.

39. Domingo P, Cabeza Mdel C, Torres F, et al. Association of thymidylate synthase polymorphisms with acute pancreatitis and/or peripheral neuropathy in HIV-infected patients on stavudine-based therapy. PLoS One 2013;8:e57347.

40. Blackett PR, Wilson DP, McNeal CJ. Secondary hypertriglyceridemia in children and adolescents. J Clin Lipidol 2015;9(5 Suppl):S29-40.

41. Schmidt HH, Genschel J, Baier P, et al. Dyslipemia in familial partial lipodystrophy caused by an R482W mutation in the LMNA gene. J Clin Endocrinol Metab 2001;86:2289-95.

42. Haque WA, Vuitch F, Garg A. Post-mortem findings in familial partial lipodystrophy, Dunnigan variety. Diabet Med 2002;19:1022-5.

43. Herbst KL, Tannock LR, Deeb SS, et al. Kobberling type of familial partial lipodystrophy: an underrecognized syndrome. Diabetes Care 2003;26:1819-24.

44. Francis GA, Li G, Casey R, et al. Peroxisomal proliferator activated receptor-gamma deficiency in a Canadian kindred with familial partial lipodystrophy type 3 (FPLD3). BMC Med Genet 2006;7:3.

45. Monajemi H, Stroes E, Hegele RA, Fliers E. Inherited lipodystrophies and the metabolic syndrome. Clin Endocrinol (Oxf) 2007;67:479-84.

46. Cao H, Alston L, Ruschman J, Hegele RA. Heterozygous CAV1 frameshift mutations (MIM 601047) in patients with atypical partial lipodystrophy and hypertriglyceridemia. Lipids Health Dis 2008;7:3. 
47. Madhra M, Noh RM, Zammitt NN, et al. A complicated pregnancy in a patient with lipodystrophic diabetes attributable to a peroxisome proliferator-activated receptor gamma (PPARG) mutation. Diabet Med 2012;29:e398-401.

48. Islek A, Sayar E, Yilmaz A, et al. A very rare cause of acute pancreatitis: Berardinelli-Seip congenital lipodystrophy. Turk J Gastroenterol 2014;25 Suppl $1: 216-9$.

49. Reue K, Brindley DN. Thematic review series: Glycerolipids. Multiple roles for lipins/phosphatidate phosphatase enzymes in lipid metabolism. J Lipid Res 2008;49:2493-503.

50. Bereziat V, Cervera P, Le Dour C, et al. LMNA mutations induce a non-inflammatory fibrosis and a brown fat-like dystrophy of enlarged cervical adipose tissue. Am J Pathol 2011;179:2443-53.

51. Vatier C, Arnaud L, Prieur X, et al. One-year metreleptin therapy decreases PCSK9 serum levels in diabetic patients with monogenic lipodystrophy syndromes. Diabetes Metab 2017;43:275-9.

\section{Figure legends}

Figure 1. Metabolic parameters after adding metreleptin to stable insulin and metformin therapy in a 70-year-old man with a delayed diagnosis of congenital generalized lipodystrophy (Patient 1).

HbA1c, glycated hemoglobin; HDL, high-density lipoprotein. 
Figure 2. Lipodystrophy in the right leg of a 6-month-old boy with Berardinelli-Seip congenital lipodystrophy type 1 (BSCL1).

Figure 3. Metabolic parameters after adding metreleptin to stable insulin and metformin therapy in a 41-year-old woman with familial partial lipodystrophy type 2 (Patient 5). HbA1c, glycated hemoglobin; HDL, high-density lipoprotein. 


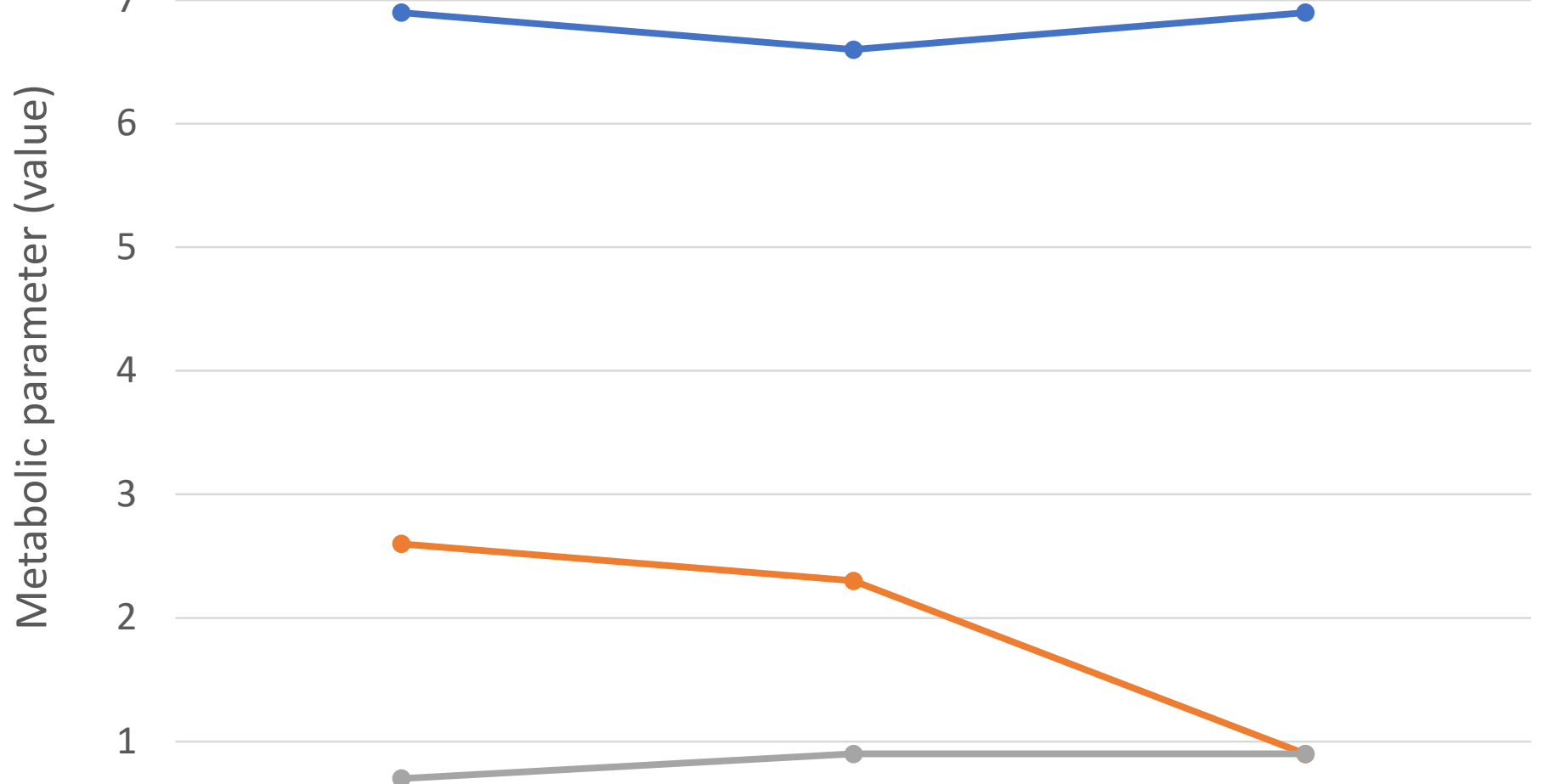

0

\begin{tabular}{|l|c|c|c|}
\multicolumn{1}{c|}{0} & Before metreleptin & 1 month & 12 months \\
\cline { 2 - 4 } \multicolumn{1}{c|}{} & 6,9 & 6,6 & 6,9 \\
\hline$\rightarrow-$ HbA1c (\%) & 2,6 & 2,3 & 0,9 \\
\hline$\rightarrow-$ Triglycerides $(\mathrm{mmol} / \mathrm{L})$ & 0,7 & 0,9 & 0,9 \\
\hline
\end{tabular}


Table 1. Evolution of metabolic parameters from day 1 (start of a low-fat diet) to month 5.5 in a 6-month-old patient with congenital generalized lipodystrophy.

\begin{tabular}{|c|c|c|c|c|}
\hline Parameter & Day $1-3$ & Day 11 & $\begin{array}{l}\text { Day 42-49 } \\
\text { (month 1.5) }\end{array}$ & Month 5.5 \\
\hline Triglycerides $[<1.7 \mathrm{mmol} / \mathrm{L}]$ & 10.90 & 6.01 & 1.07 & 0.92 \\
\hline Total cholesterol $[<4.0 \mathrm{mmol} / \mathrm{L}]$ & 5.55 & 3.25 & 3.18 & 2.53 \\
\hline AST [10-40 IU/L] & 111 & 227 & 97 & 30 \\
\hline ALT [7-56 IU/L] & 143 & 118 & 90 & 16 \\
\hline Prothrombin time [70-100\%] & 60 & 83 & - & - \\
\hline Fasting blood glucose $[<5.6 \mathrm{mmol} / \mathrm{L}]$ & - & - & 7.7 & 4.8 \\
\hline Fasting insulin $[<10 \mathrm{mIU} / \mathrm{L}]$ & - & - & 254.0 & 2.3 \\
\hline HOMA-IR [0.5-1.4] & - & - & 87.00 & 0.49 \\
\hline Albumin $[35-55 \mathrm{~g} / \mathrm{L}]$ & 22.4 & - & - & 46.7 \\
\hline $\begin{array}{l}\text { Hemoglobin [men: } 13.5-17.5 \mathrm{~g} / \mathrm{dL} \text {; } \\
\text { women: } 12.0-15.5 \mathrm{~g} / \mathrm{dL} \text { ] }\end{array}$ & 6.9 & 12.8 & 9.1 & 10.1 \\
\hline $\mathrm{pH}[7.4]$ & 7.30 & 7.42 & - & - \\
\hline Lactate $[0.1-1 \mathrm{mmol} / \mathrm{L}]$ & 10.50 & 5.30 & 0.69 & - \\
\hline
\end{tabular}


ALT, alanine aminotransferase; AST, aspartate aminotransferase; HOMA-IR, homeostasis model assessment of insulin resistance.

The patient was treated with parenteral nutrition from Day 2 to Day 49. 